\title{
Study of a Melt Crystallization Process for Seawater
}

\section{Desalination}

Anouar Rich ${ }^{1}$, Mostapha Siniti ${ }^{1}$, Denis Mangin ${ }^{2}$, Jean-Paul Klein ${ }^{2}$, Youssef Mandri ${ }^{2}{ }^{3}$, Tijani Bounahmidi ${ }^{3}$, Ahmed Bouhaouss $^{4}$, Stéphane Veesler ${ }^{5}$ and Mohamed El Ganaoui ${ }^{6}$

1. Equipe de Thermodynamique, Surface et Catalyse, Faculté des Sciences, Université Chouaïb Doukkali, El Jadida 24000, Maroc

2. LAGEP (Laboratoire d'Automatique et de Génie des Procédés), Université Lyon 1, Villeurbanne 69622, France

3. LASPI (Laboratoire d'Analyse et Synthèse des Procédés Industriels), Ecole Mohammadia d'Ingénieurs, Université Mohammed V, Rabat 10000, Maroc

4. LNGPE (Laboratoire des Nanostructures, Génie des Procédés et Environnement), Faculté des Sciences de Rabat, Université Mohammed V, Rabat 10000, Maroc

5. CINaM-CNRS (Centre Interdisciplinaire de Nanosciences de Marseille-Centre National de la Recherche Scientifique), Campus de Luminy, Marseille 13288, France

6. LERMAB-IUT (Laboratoire d'Etude et de Recherche sur le Matériau Bois-Institut Universitaire de Technologie Longwy), Longwy, Université de Lorraine, Cosnes et Romain F-54400, France

Received: November 20, 2014 / Accepted: December 02, 2014 / Published: January 25, 2015.

\begin{abstract}
The work aims to develop a process for freezing desalination of seawater on cold walls. The experiments were performed with water $/ \mathrm{NaCl}$ solutions of different concentrations and with samples of seawater. The pilot crystallizer consists of a cooled tube immersed in a cylindrical double jacketed tank containing water to be treated. The complete process of desalination is conducted in two steps: the freezing step, leading to the crystallization of the ice layer and the sweating step, which consists of purifying the ice layer in depth by melting the impure zones. The systematic study of the influence of operating parameters has highlighted the important role of the cooling ramp and salinity of the solution on the purity of the ice produced. In the absence of stirring, the temperature of the double jacket also has a noticeable effect on the purity of the ice due to temperature gradients, and consequently, convection currents that may result in the solution. The results of this work show the feasibility of the technique and give a good indication of operating conditions that can be used to produce drinking water.
\end{abstract}

Key words: Desalination, seawater, melts crystallization, sweating.

\section{Nomenclature}

$T_{F R, 0} \quad$ the initial temperature of bath $n^{\circ} 1\left({ }^{\circ} \mathrm{C}\right)$

$\Delta t_{F R}$ the cooling time (h)

$\Delta T$ the temperature difference between initial temperature

$\Delta T \quad\left(T_{F R, 0}\right)$ and temperature of the double jacket $\left(T_{D J}\right)\left({ }^{\circ} \mathrm{C}\right)$

$T_{1} \quad$ the solution temperature $\left({ }^{\circ} \mathrm{C}\right)$

$T_{4} \quad$ outlet temperature of coolant in the tube $\left({ }^{\circ} \mathrm{C}\right)$

$T_{\text {bain } 1}$ temperature in the bath 1 which feeds the tube $\left({ }^{\circ} \mathrm{C}\right)$

$T_{3} \quad$ inlet temperature of cooling in the tube $\left({ }^{\circ} \mathrm{C}\right)$

Corresponding author: Anouar Rich, professor, research fields: water, vapor/liquid/solid equilibrium, crystallization and precipitation. E-mail: rich.anouar7@gmail.com.
$T_{5} \quad$ inlet temperature of cooling in the double jacket $\left({ }^{\circ} \mathrm{C}\right)$

$T_{6} \quad$ outlet temperature of cooling in the double jacket $\left({ }^{\circ} \mathrm{C}\right)$

$T_{F R, 1}$ the final temperature of the bath $n^{\circ} 1\left({ }^{\circ} \mathrm{C}\right)$

$T_{D J} \quad$ the temperature of the double jacket $\left({ }^{\circ} \mathrm{C}\right)$

$T_{S W} \quad$ the sweating temperature $\left({ }^{\circ} \mathrm{C}\right)$

$\Delta t_{S W} \quad$ duration of sweating (h)

$C_{i c e, 1}$ the ice salinity after the freezing step $(\mathrm{g} / \mathrm{kg})$

$C_{i c e, 2}$ the salinity of the final ice layer after the draining step

$C_{i c e, 2}$ or the sweating step $(\mathrm{g} / \mathrm{kg})$

$V_{F R}$ the average growth rate of ice $(\mathrm{mm} / \mathrm{h})$

$V_{C O}$ the cooling rate $\left({ }^{\circ} \mathrm{C} / \mathrm{h}\right)$

$T_{\text {bain } 2}$ temperature in the bath $\mathrm{n}^{\circ} 2$ which feeds the double jacket $\left({ }^{\circ} \mathrm{C}\right)$ 


\section{Introduction}

Energy and water are essential to the development of any human community. Water is our most precious natural resource. Desalination of seawater is one of the most promising options to ensure the drinking water supply.

The technique of freezing has been proposed as an alternative to distillation and reverse osmosis for desalination in several studies [1-3].

Desalination by freezing could present some advantages versus other techniques. The method has the advantage of having a low environmental impact: reverse osmosis used membranes in fact onerous and very sensitive to the problem of clogging, requiring pre-treatment pushed seawater. The process by freezing is also less corrosion problems and scaling as distillation, given the low levels of working temperatures. It can theoretically allow an energy gain from the distillation because the heat of fusion of ice is seven times lower than the heat of vaporization of water. Thus, the energy cost of desalination by freezing may be competitive with that of reverse osmosis and distillation. This work is a continuation of previous work. In earlier work, freezing indirect were made either in static mode in which the solution is stagnant $[4,5]$ or by agitation mode that the brine was induced by air bubbling [6]. The results presented here are a comparison between the two operating modes in order to quantify the influence of operating conditions of the desalination process by freezing the purity of the ice to produce fresh water.

The paper is organized as follows: Section 2 presents the experimental setup used to obtain measurements; Section 3 presents the obtained experimental results of the study of freezing phenomenon and sweating step; Section 4 gives conclusions and presents information about the continuation of this work.

\section{Experimental Setup}

Fig. 1 represents the experimental setup. The crystallizer was composed of a stainless steel tube immersed inside a cylindrical glass tank equipped with a double jacket. The solution was introduced in

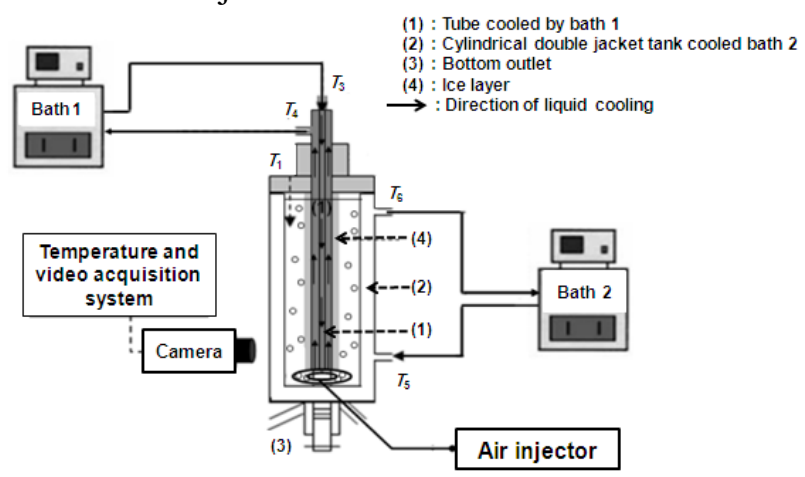

Fig. 1 Experimental setup.

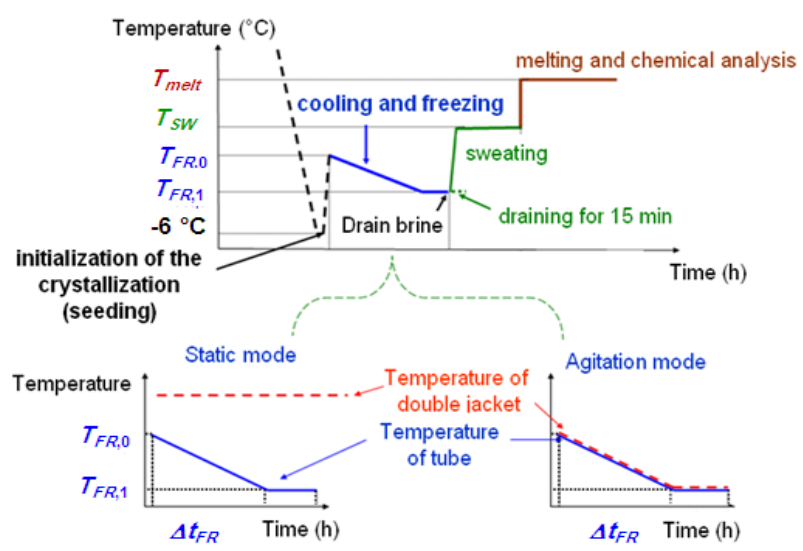

Fig. 2 Main steps and operating conditions of the desalination process in static and agitated modes.

the glass tank. The freezing step led to the formation of an ice layer on the external surface of the tube. At its base, the tube is coated with teflon tape to prevent crystallization in the area. A camera, was used to film the ice layer and then measure its growth kinetics. Two thermostatic baths were used to set the cooling rate in the tube and in the double jacketed tank, respectively. The different temperatures were measured and recorded continuously using a data acquisition system. Different saline solutions were used for the experiments: $\mathrm{NaCl} /$ water solutions and seawaters from Rabat (37.6 g/kg), Marseille (38.6 $\mathrm{g} / \mathrm{kg}$ ) and Nice (39.1 g/kg). Fig. 2 includes the steps and the operating conditions applied to the desalination process. The process is divided into five main steps: 
(1) Initialization of the crystallization or seed: the initialization was done as follows: the tube was cooled to $-6{ }^{\circ} \mathrm{C}$ and plunged in distilled water in order to form a seed layer on the surface of the tube. The tube was next quickly heated to the chosen initial temperature of the freezing step and introduced in the glass tank filled with of saline solution, preliminary brought at the same initial temperature $\left(T_{F R, 0}\right)$.

(2) Cooling and freezing: this step was performed in two modes:

- In static mode in which the solution is stagnant, trials are usually conducted by maintaining the temperature of the double jacket constant and performing a cooling ramp into the tube;

- Agitation mode in which the agitated of the solution is achieved by injecting air (flow rate $=21.5$ $\mathrm{cm}^{3} / \mathrm{s}$ ) through a ring placed at the bottom of the tank and pierced with four holes of $1 \mathrm{~mm}$ in diameter. Similar linear cooling rates were applied in both the tube and the double jacket of the glass tank. At the end, the chosen final temperature of the freezing step was kept constant for one hour. The mass of solution introduced is $300 \mathrm{~g}$ static mode and $280 \mathrm{~g}$ agitation mode.

(3) Drain brine: the residual brine was evacuated through the bottom outlet.

(4) Draining or sweating: after the freezing step, two types of purification of the ice:

- The first type of purification is a simple draining operated by keeping the tube covered with ice in the tank empty double wrapped and at $0{ }^{\circ} \mathrm{C}$ for $15 \mathrm{~min}$;

- The second type of purification of the ice layer is sweating which allows purify down the ice by making a merger of the impure. It consists of a controlled heating of the crystalline layer in order to melt the crystal sections in contact with the solution pockets trapped inside of the layer. Indeed, the ice layer is impure because of these brine pockets formed during the layer growth. Sweating is then able to purify the interior of the ice layer by draining out the trapped solution pockets. In all the experiments, a ramp of
$0.17 \mathrm{~h}$ was applied to reach the chosen sweating temperature in the tube and the tank double jacket; the sweating temperature was then kept constant during the whole sweating step.

(5) Fusion: the remaining purified ice layer was finally recovered by completely melting it.

The salinities of the different solutions collected (brine, drained out liquid or sweating liquid and melted purified ice) were measured and the mass balance was verified. The salinities were assimilated to the total dissolved solids measured by water evaporation at $100{ }^{\circ} \mathrm{C}$ for the $\mathrm{NaCl} /$ water solutions and at $180^{\circ} \mathrm{C}$ for the sea water solutions.

The operating parameters of the freezing step were: the initial temperature $\left(T_{F R, 0}\right)$ and the final temperature $\left(T_{F R, 1}\right)$ in baths $\mathrm{n}^{\circ} 1$ and 2 , the cooling time $\left(\Delta t_{F R, 0}\right)$, the type and the salinity of the initial solution $\left(C_{s o l, 0}\right)$. The operating parameters of the sweating step were: the temperature set in the tube and in the tank double jacket $\left(T_{S W}\right)$, and the duration of the sweating step $\left(\Delta t_{S W}\right)$.

\section{Results}

\subsection{Study of the Freezing Step}

3.1.1 Influence of the Initial Temperature of the Cold Wall

Fig. 3 presents the effect of initial temperature on the purity of the ice for preliminary tests conducted in static mode with seawater in Rabat and Rabat seawater diluted. Fig. 3 shows that, for each solution, there was an optimal temperature, which led to the lowest ice salinity. A difference of $0.1{ }^{\circ} \mathrm{C}$ to $0.2^{\circ} \mathrm{C}$ compared to the optimal temperature can lead to a final salinity of the ice above $1 \mathrm{~g} / \mathrm{kg}$. Fig. 4 compares the ice thickness evolution measured by video for three different initial temperatures with solutions of sea water diluted. Fig. 4 helps to explain the effect of initial temperature. The initial temperature of the cooling ramp that gives the best pure ice is equal to $T_{F R, 0}=-1.2^{\circ} \mathrm{C}$. In this case, the thickness of the ice layer grows almost linearly for the duration (5 h) 
which is applied during the cooling ramp. If the initial temperature is below the optimum temperature, the initial growth is faster. If the initial temperature is

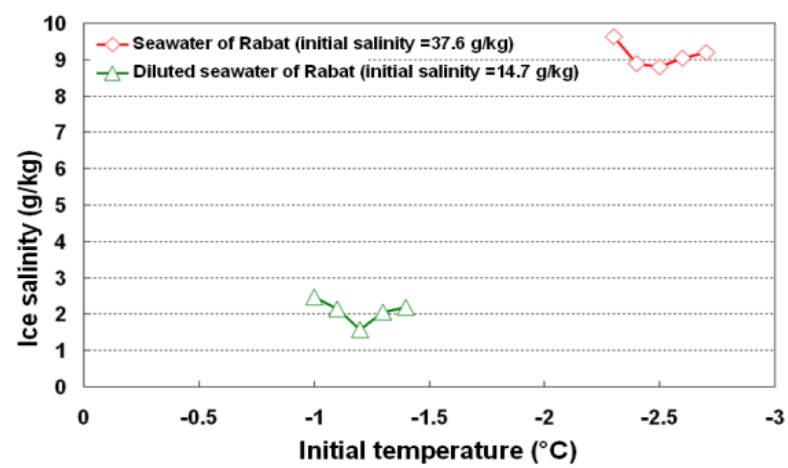

Fig. 3 Effect of the initial temperature on the ice salinity in freezing static mode for seawater in Rabat and diluted seawater of Rabat.

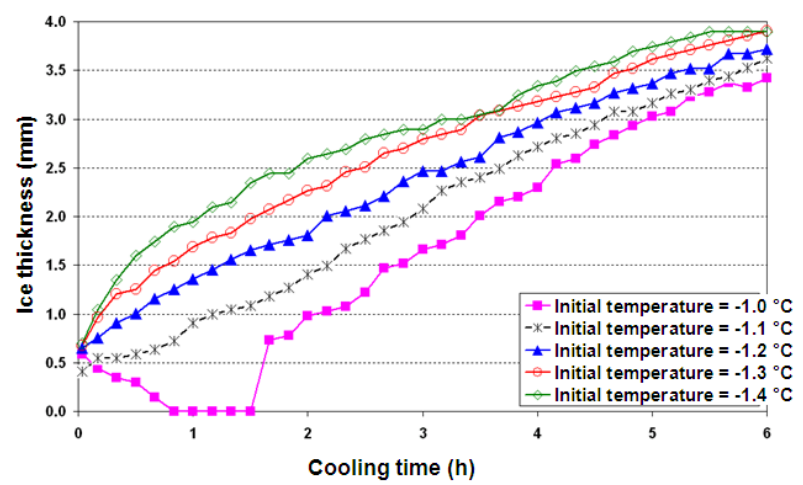

Fig. 4 Evolution of the ice thickness for different initial temperatures for diluted seawater Rabat of initial salinity $14.7 \mathrm{~g} / \mathrm{kg}$.

higher than the optimum temperature $\left(T_{F R, 0}=-1.1^{\circ} \mathrm{C}\right)$, growth is initially very low, and then becomes faster than that observed with optimal $T_{F R, 0}$. It is therefore not surprising that the inclusion rate is higher if the distance from the initial temperature optimum. When the initial temperature is equal to $T_{F R, 0}=-1{ }^{\circ} \mathrm{C}$, there is even a merger of the seed layer.

3.1.2 Effects of the Ice Growth Rate and of the Initial Solution Salinity

Fig. 5 shows the effects of the mean growth rate of ice and that the initial solution salinity on the purity of the ice for trials conducted in static and agitation modes. A high growth rate or high cooling rate results in a period of rapid cooling, the rate incorporation of solution pockets increases. A change of the growth mechanism, a change in the process of incorporating

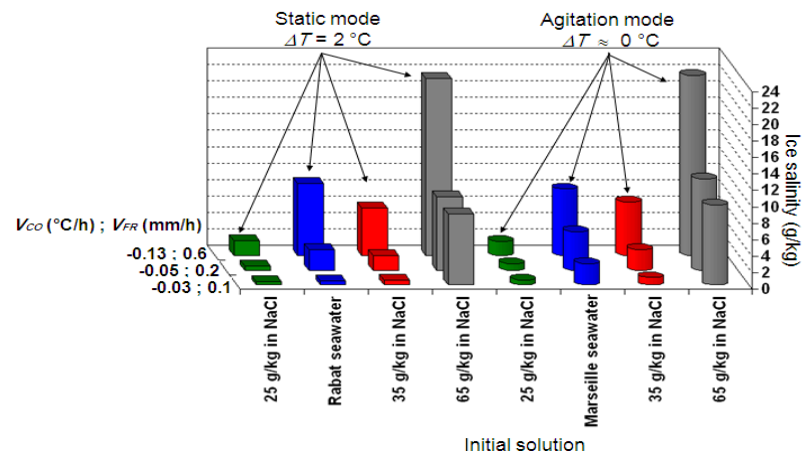

Fig. 5 Ice salinity versus initial solution for different ice growth rates; $V_{F R}$ and $V_{C O}$ corresponds respectively to the average growth rate and cooling rate.

inclusions and the different types of inclusions in ice incorporated depending on the cooling rate and the initial solution salinity could explain this result as shown by Weeks and Ackely [7]. Salinity at the interface ice/solution may also be higher in high growth rate, because the salt rejection during growth and over the initial solution salinity is increasing, the salinity of the interface also increases. It also appears in Fig. 5 in agitation mode and a temperature difference of low $\Delta T=0{ }^{\circ} \mathrm{C}$ between the jacket and the tube, salinities obtained are substantially the same as those that were obtained without agitation and by imposing a temperature difference of $\Delta T=2{ }^{\circ} \mathrm{C}$ for different solutions of $\mathrm{NaCl}$ concentration and seawater.

The agitation seems to have the beneficial effect expected, renewing interface ice/solution and as a result reducing the salt concentration solution bags incorporated into the ice. The ice layers formed in agitated fashion are also smooth, despite the low thermal gradient. Indeed, the solution seems to be every moment in equilibrium with ice [6]. But in the absence of stirring, the temperature of the jacket also has a noticeable effect on the purity of the ice due to temperature gradients, and consequently, convection currents that may be created in the solution. In the next section, we analyze the effect of temperature gradient on the purity of the ice in detail.

\subsubsection{Effect of Temperature Gradient}

Fig. 6 shows the shape of temperature profiles and 


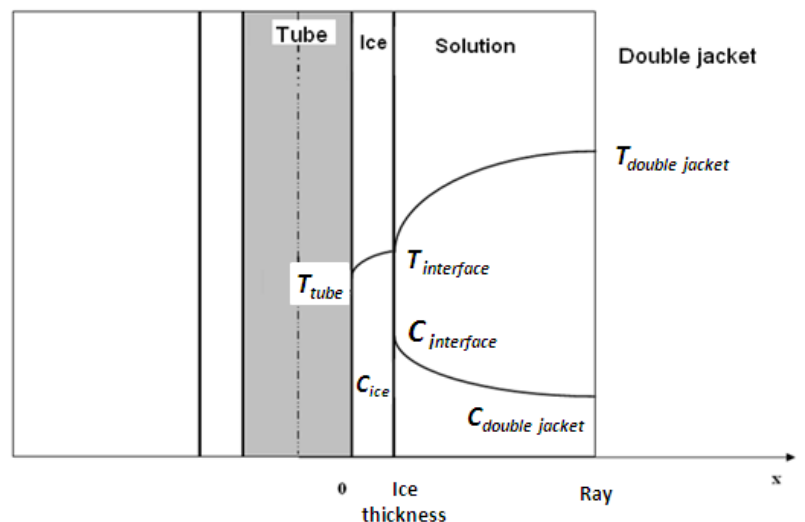

Fig. 6 Temperature and concentration profiles in the solid and solution in static mode.

concentration in the annular space of the crystallizer in the presence of such a gradient in the static mode. Freezing is carried out by imposing a cooling ramp in the tube and holding the temperature of the jacket constant. The concentration gradient in the solution is generated by salt rejection during ice growth. The temperature at the interface ice/solution tends, meanwhile, continued to increase in heat release by freezing, following the increase in the concentration resulting in a decrease in the equilibrium temperature and because of the high thermal resistance of the solid. Fig. 7 shows the effect of initial thermal gradient $(\Delta T)$ between the double jacket and the tube on the purity ice growth rate in average ice between $0.1 \mathrm{~mm} / \mathrm{h}$ and $0.6 \mathrm{~mm} / \mathrm{h}$ in static and agitated modes solution for three types: seawater of Rabat, Rabat seawater diluted and seawater of Marseille with initial salinity respectively of $37.6 \mathrm{~g} / \mathrm{kg}, 14.7 \mathrm{~g} / \mathrm{kg}$ and $39.1 \mathrm{~g} / \mathrm{kg}$. Fig. 7 shows that for seawater in static mode, the purity of ice clearly improves when $\Delta T$ increases, which is growth data speed. However, the increased thermal gradient between the double jacket and the tube seems not to influence the purity of the ice formed for freezing conducted with diluted seawater salinity of $14.7 \mathrm{~g} / \mathrm{kg}$.

Fig. 8a presents operating conditions applied in the tests in static mode at different average growth rates versus time cooling for seawater of Rabat and followed by the measured temperatures of the solution and then by imposing the initial temperature gradient

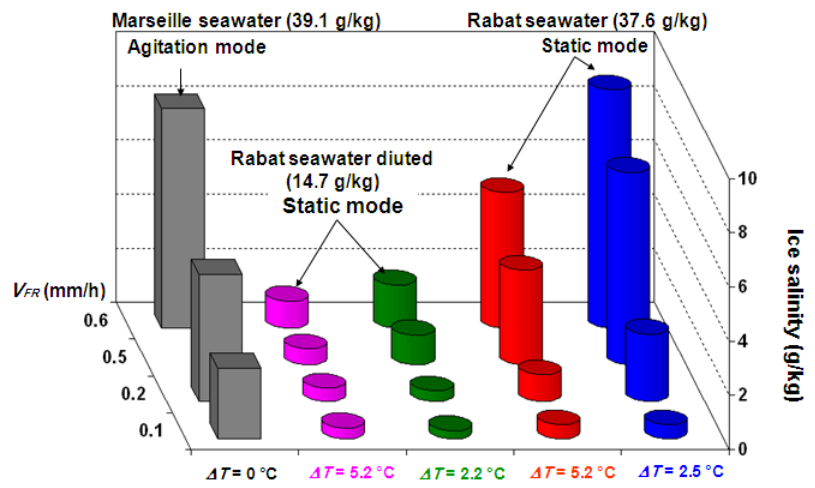

Fig. 7 Effect of thermal gradient $(\Delta T)$ between the double jacket and the tube on the purity ice at different mean growth rate of ice.
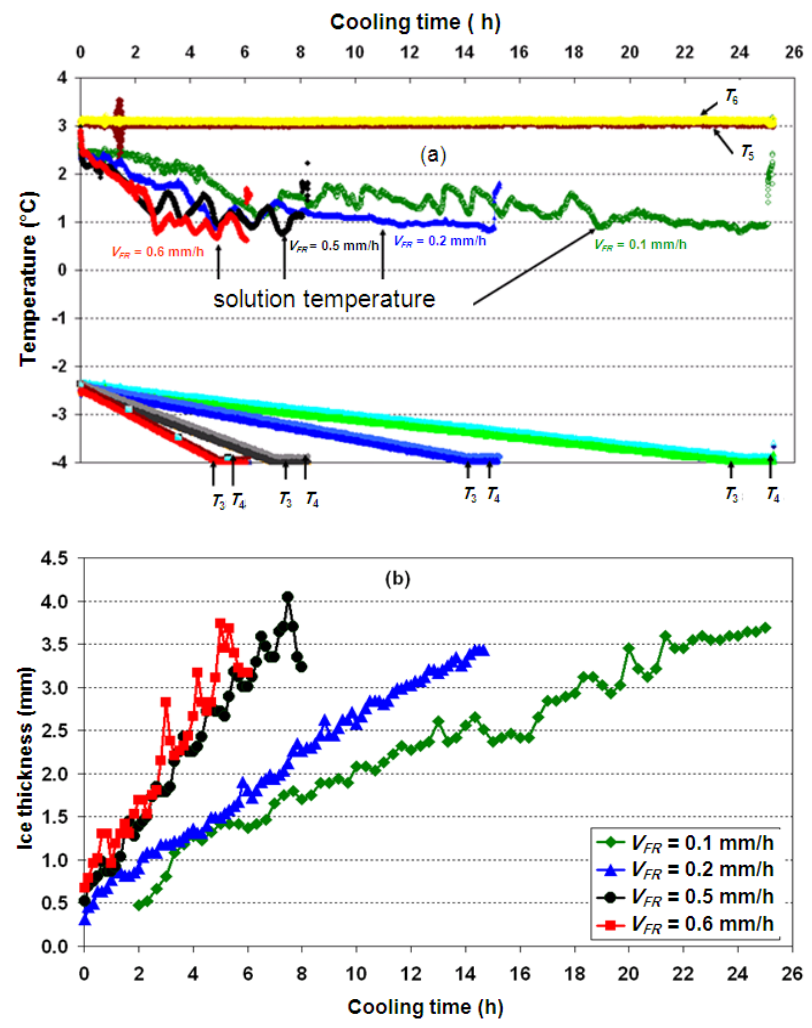

Fig. 8 (a) Operating conditions applied in the tests in static mode at different average growth rates versus time cooling for seawater of Rabat and followed by the measured temperatures of the solution; and (b) evolution of the thickness of ice.

$\Delta T=5.2^{\circ} \mathrm{C}$. The temperature of the solution is taken at a distance of about $0.8 \mathrm{~mm}$ of the external wall of the tube. Fig. 8a shows the evolution of temperature of the solution revealed oscillations measured for all tests. These oscillations become much more intense, high thermal gradient $(\Delta T)$ applied through the solution. 
They were interpreted as being due to the existence of convection currents in the solution. The ink injection into the solution confirmed the existence of these convection currents in the solution. The temperature difference applied between the double jacket and the tube implies the existence of a thermal gradient through the solution: the solution is cold at the interface ice/solution and hot in the vicinity of the wall of the tank. In this case, the cold solution in equilibrium at the interface is always denser than the hot solution close to the jacket. Fig. 10 shows the curve of the evolution of the density as a function of temperature for seawater salinity of $37.6 \mathrm{~g} / \mathrm{kg}$. The curve of density was obtained from the state equation of seawater [9]. The projection of the imposed temperature in the double jacket and the tube shows that the density of the solution varies between 1,029.94 and 1,030.35 g/l (the maximum density) for the duration of cooling. Therefore, it must form convection currents, with a downward movement in the vicinity of the interface and an upward movement in the vicinity of the wall of the tank. However, it should be remembered that, during the freezing step, the growing ice rejects salt to the solution and concentration gradients, therefore, should also appear in the solution, especially if growth is rapid. The solution at the interface more salt ice/solution is then denser than the solution of the tank.

Fig. $8 \mathrm{~b}$ shows the evolution of the thickness of the layer of ice as a function of time, measured using the video acquisition system, for testing of Fig. 9a. Note that the curves of the evolution of ice thickness are disrupted. These perturbations are related to cycles of melting/growth of the layer, clearly visible on the videos. The images in Figs. 10a and 10b confirm the irregularity of the ice thickness obtained at the end of freezing in two different growth rates. The cycle's fusion/growth of the layer of ice is probably induced by the displacement of convection loops in the time.

Thus, convection currents can reduce the salt concentration gradient at the interface ice/solution

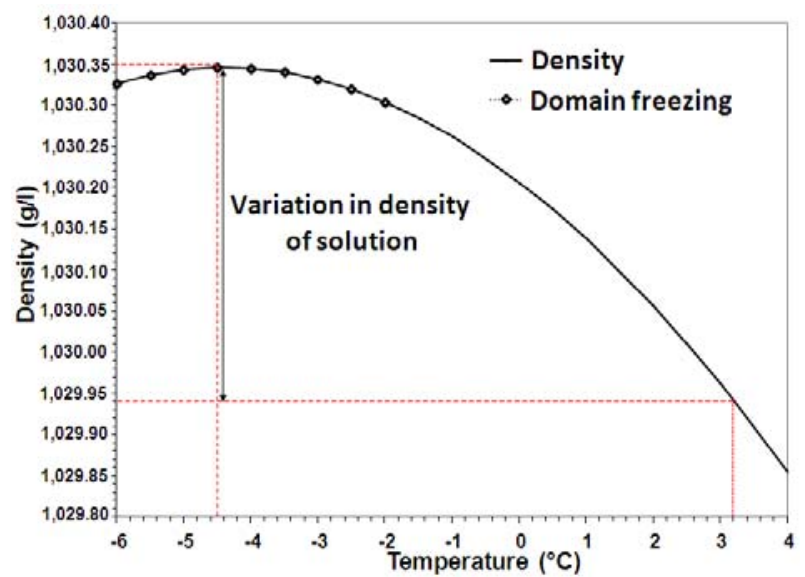

Fig. 9 Evolution of density as a function of temperature for seawater salinity of $37.6 \mathrm{~g} / \mathrm{kg}$.

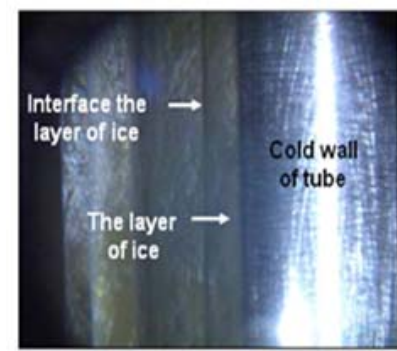

a) Ice salinity $=0.5 \mathrm{~g} / \mathrm{kg}$ $V_{F R}=0.1 \mathrm{~mm} / \mathrm{h}$

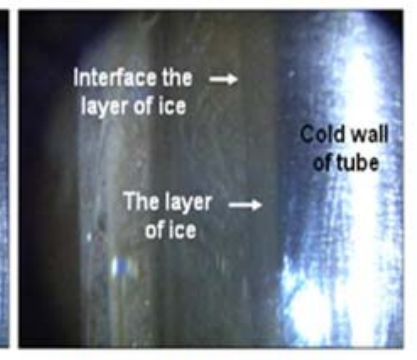

b) Ice salinity $=8.8 \mathrm{~g} / \mathrm{kg}$ $V_{F R}=0.6 \mathrm{~mm} / \mathrm{h}$
Fig. 10 Images acquired by the video camera of ice formed from seawater of Rabat in static mode in different growth rates.

during the growth and to induce the phenomenon of fusion/growth that smooth layer and reduces the rate of inclusions. Fig. 9 also shows that the ice is more transparent when the rate of growth is slow. Consideration of all of these phenomena's precise requirements call for simultaneous model combining the mass transfer and heat with flows. Moreover, the energy consumption of the process by freezing was also calculated in a recent study. The study indicated that the process in static mode is lower than the mode process in agitated because of agitation by bubbling the solution that requires additional consumption. The energy consumption to produce $1 \mathrm{~m}^{3}$ of fresh water is about $8 \mathrm{KWh} / \mathrm{m}^{3}$ in static mode and $24 \mathrm{KWh} / \mathrm{m}^{3}$ in agitation mode. This means that the freezing method can be competitive for reverse osmosis and distillation consumes between $3.5 \mathrm{KWh} / \mathrm{m}^{3}$ and $5 \mathrm{KWh} / \mathrm{m}^{3}$, respectively for the first and the order $20 \mathrm{kWh} / \mathrm{m}^{3}$ for 
the second [7].

\subsection{Study of the Sweating Step}

The key parameters of sweating are the initial salinity of the ice after freezing step $\left(C_{i c e, 1}\right)$, time to sweating $\left(\Delta t_{S W}\right)$ and temperature sweating $\left(T_{S W}\right)$. Fig. 11 recorded using the video camera presents the appearance of the ice during the step of sweating from seawater from Nice. Fig. 11 shows photos captured with the video camera during the sweating step. Many cracks appeared in the layer. These cracks can explain why purification in depth was possible. Fig. 12 shows the results of the sweating experiments performed with ice layers formed from the three sea waters. In each experiment, the drained out liquid was regularly collected to measure its salinity. The time evolution of the ice salinity could then be calculated. Overall, sweating strongly improves the ice purity. These results highlight the essential role of the sweating step. For given sweating conditions, the ice purity after sweating is better when the initial ice concentration is lower (sea water of Nice and $T_{S W}=-0.4{ }^{\circ} \mathrm{C}$, or Rabat sea water and $T_{S W}=-0.1{ }^{\circ} \mathrm{C}$ ). However, for severe sweating conditions, the final salinities become almost similar, whatever the initial ice purity (Marseille sea water and $T_{S W}=0{ }^{\circ} \mathrm{C}$ ). The effect of the sweating temperature $T_{S W}$ is very strong. Thus, at $T_{S W}=-0.1^{\circ} \mathrm{C}$, only the ice obtained after a freezing step of $24 \mathrm{~h}$ could give a final layer of salinity less than $0.5 \mathrm{~g} / \mathrm{kg}$, i.e., satisfying the drinking water standards. At $T_{S W}=$ $0{ }^{\circ} \mathrm{C}$, both layers formed by a freezing step of $14 \mathrm{~h}$ and $5 \mathrm{~h}$ gave drinking water after the sweating step.

The sweating time $\Delta t_{S W}$ is also important. The decrease in salinity is strong at the beginning. Then, each curve seems to reach a plateau. The plateau is reached after 3-4 h, depending on the operating conditions. These times correspond to the optimal sweating times. Obviously, the mass loss during the sweating step is directly linked to the purification rate. The yields of sweating obtained for the three cases which led to drinking water are compared. For

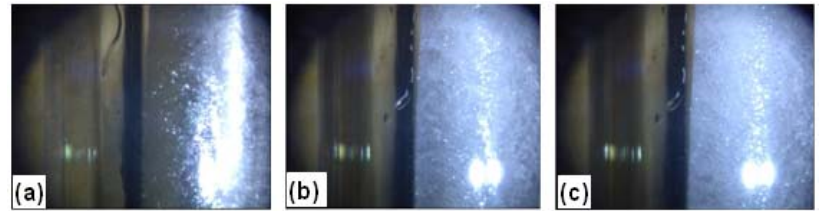

Fig. 11 Aspect of the ice layer during the sweating step of run 30; (a) $\Delta t_{S W}=0 \mathrm{~h}, C_{i c e, 1}=8.1 \mathrm{~g} / \mathrm{kg}$; (b) $\Delta t_{S W}=1 \mathrm{~h}, C_{i c e, 2}=$ $1.2 \mathrm{~g} / \mathrm{kg}$ and (c) $\Delta t_{S W}=2 \mathrm{~h}, C_{i c e, 2}=0.7 \mathrm{~g} / \mathrm{kg}$.
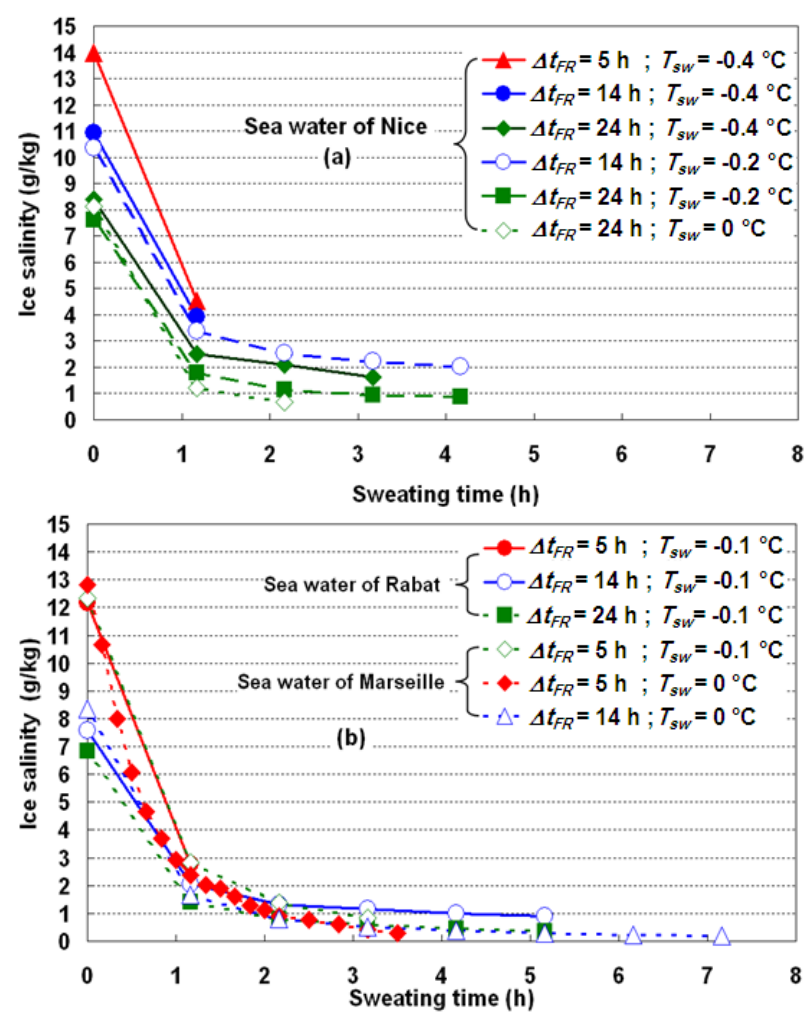

Fig. 12 Ice salinity as a function of the sweating time, for different sweating temperatures; the initial ice layers were formed from sea waters of (a) Nice, (b) Rabat and Marseille, with different freezing times.

instance, the shortest process ( $5 \mathrm{~h}$ of freezing and $3 \mathrm{~h}$ of sweating at $0{ }^{\circ} \mathrm{C}$ ) has a yield of $40 \%$. However, taking into account the solution pockets contained in the layer before sweating, this yield of $40 \%$ means that less than $50 \%$ of the pure ice was melted during the sweating step. The longest process ( $24 \mathrm{~h}$ of freezing and $4 \mathrm{~h}$ of sweating at $-0.1^{\circ} \mathrm{C}$ ) has a yield of $65 \%$, which means that less than $25 \%$ of the pure ice was melted during the sweating step. Since yield affects directly the energy consumption, an optimum has to be found between the duration of the global process and its yield. Moreover, the ice layer obtained 
at the end of the shortest process was quite fragile. It probably stayed stick on the tube surface thanks to the seed layer which was deposited during the crystallization initialization. Thus, the solidity of the residual layer has also to be studied for the process scale up.

\section{Conclusions}

The study helps to identify the operating conditions to implement in a desalination process of seawater by freezing cold wall. It is important to drive the crystallization with precision to get an ice as pure as possible. The ice layer formed in the freezing step is contaminated by liquid inclusions containing the impurities. Its purity is dependent on the initial temperature, on the growth rate and on the solution salinity. In static mode, it appeared that the thermal gradient imposed through the annular space between the tube and the double jacket induces the existence of convection currents. Such currents provide a better solution renewal at the interface of the ice and as a result reduce the concentration of solution bags incorporated in the layer of ice favouring the formation of a higher purity ice. The stage of sweating can significantly increase the purity of the ice, by the deep cleansing solution bags. Experiments show the feasibility of achieving the standards of drinking water. The development of this process requires a continuation of work on: optimization steps of freezing and sweating modelling of mass transfer and heat must be developed to refine the interpretation of phenomena and coupled effects of operating parameters; integration of the overall process combining the steps of freezing, of sweating and of melting with the refrigerating machine. Finally, be considered technologically in order to propose a design and a procedure for this overall process. This will then allow access to the estimate of the true cost of energy taking into account the heat losses and the operation of the machine.

\section{Acknowledgments}

This study was supported by the French-Moroccan Committee (Comité Mixte Interuniversitaire Franco-Marocain), Hubert Curien/Volubilis program (Action Integrée $\left.\mathrm{N}^{\circ} \mathrm{MA} / 06 / 150\right)$ and the Committee is gratefully acknowledged.

\section{References}

[1] Luo, C. S., Chen, W. W., and Han, W. F. 2010. "Experimental Study on Factors Affecting the Quality of Ice Crystal during the Freezing Concentration for the Brackish Water.” Desalination 260: 231-8.

[2] Lixin, X., Jia, M., Fang, C., Pingli, L., Jie, L., Weibin, C., and Shichang, W. 2009. "Study on Sea Ice Desalination Technology.” Desalination 245: 146-54.

[3] Garcia, A. R. 2004. "Study of freezing as a new technique of water treatment: specific applications.” Ph.D. thesis, INSA Toulouse, France.

[4] Anouar, R. 2010. "Freezing Desalination of Sea Water in a Static Layer Crystallizer." Desalination and Water Treatment 13: 120-7.

[5] Youssef, M. 2011. "Parametric Study of the Sweating Step in the Seawater Desalination Process by Indirect Freezing.” Desalination 269 (1-3): 142-7.

[6] Anouar, R. 2012. "Seawater Desalination by Dynamic Layer Melt Crystallization: Parametric Study of the Freezing and Sweating Steps.” Journal of Crystal Growth 342 (1): 110-6.

[7] Weeks, W. F., and Ackley, S. F. 1986. The Growth, Structure and Properties of Sea Ice. The Geophysics of Sea Ice.

[8] Youssef, M. 2011. "Parametric Study of Sea Water Desalination Process by Indirect Freezing.” Ph.D. thesis, University Mohammed V Agdal Rabat cotutelle with the University Claude Bernard Lyon 1.

[9] UNESCO. 1981, "Tenth Report of the Joint Panel on Oceanographic Tables and Standard.” Technical papers in Marine Sciences. 